\title{
Frontline Maintenance Treatment for Ovarian Cancer
}

\author{
Osnat Elyashiv ${ }^{1,2}$ (D) $\cdot$ Yien Ning Sophia Wong ${ }^{1,2}$ (D) Jonathan A. Ledermann ${ }^{1,2}$ (D)
}

Accepted: 3 May 2021 / Published online: 14 June 2021

(C) The Author(s) 2021

\begin{abstract}
Purpose of Review Advanced epithelial ovarian cancer remains the most lethal gynaecological cancer. Most patients with advanced disease will relapse within 3 years after primary treatment with surgery and chemotherapy. Recurrences become increasing difficult to treat due to the emergence of drug resistance and 5-year survival has changed little over the last decade. Maintenance treatment, here defined as treatment given beyond primary chemotherapy, can both consolidate the response and prolong the control of disease which is an approach to improve survival.

Recent Findings Here we review maintenance strategies such as targeting angiogenesis, interference of DNA repair through inhibition of PARP, combinations of targeting agents, and immunotherapy and hormonal therapy.

Summary Much has been learnt from the success and challenges of these treatments that have in the last few years which led to significant reduction in disease recurrence, changed the guidelines for treatment, and established a new paradigm for the treatment of ovarian cancer.
\end{abstract}

Keywords Epithelial ovarian cancer - Fallopian tube cancer - Primary peritoneal cancer - Frontline maintenance treatment . Antiangiogenic agents $\cdot$ PARP inhibitors $\cdot$ Checkpoint inhibitors $\cdot$ Targeted therapies $\cdot$ Combined targeted therapies $\cdot$ Hormonal maintenance treatment

\section{Introduction}

Epithelial ovarian cancer (EOC) continues to be the leading cause of death from gynaecological malignancies. Worldwide, there are an estimated 295,000 cases and 184,000 ovarian cancer related-deaths documented in 2018[1]. Most patients present at advanced stage, which contributes to the high mortality rate. About $70 \%$ of all EOC are high grade serous tumours, most probably originating in the distal fallopian tube [2]. Other high-grade tumours of

This article is part of the Topical Collection on Gynecologic Cancers

Osnat Elyashiv

o.elyashiv@ucl.ac.uk; osnatelyashiv@gmail.com

Yien Ning Sophia Wong

sophia.wong@ucl.ac.uk

Jonathan A. Ledermann

j.ledermann@ucl.ac.uk

1 UCL Cancer Institute, University College CRUK and UCL Cancer Trials Centre, London WC1E 6DD, UK

2 University College London Hospital, 235 Euston Rd, Fitzrovia, London NW1 2BU, UK endometrioid or clear cell subtype are generally managed in the same way as the more common serous ovarian cancers. It is also now clear that a significant fraction of high grade EOC with non-mucinous histology, particularly the serous subtype, has an underlying hereditary cause. Around $20-25 \%$ of high grade serous EOC are associated with germline mutations in BRCA1/2 genes [3], and additional 5-7\% of patients harbour somatic BRCA1/2 mutations [4]. Other rarer gene mutations, such as those associated with Lynch syndrome, are also found in association with ovarian cancers. The combination of cytoreductive surgical debulking followed by a platinumbased chemotherapy has been the mainstay of treatment for more than two decades. Maximal surgical effort resulting in no visible residual macroscopic disease yields the best outcome [5]. Despite good clinical response to primary treatment, the majority of patients with advanced stage disease experience disease relapse at 18 months [6]. Thereafter, the median survival is around 2 years [7].

The concept of maintenance treatment with further chemotherapy evolved from treatment of acute leukaemia and has also been applied to ovarian cancer. However, the success of this approach has not been established in solid tumours, including ovarian cancer. Prolonged therapy with, for example, low dose alkylating agents to consolidate the response and 
maintenance symptom (disease) control increases the risk of toxicity, including secondary leukaemia [8]. However, one trial in ovarian cancer conducted by the Southwest Oncology Group (SWOG) and Gynecologic Oncology Group (GOG) using maintenance paclitaxel for 12 or 3 months showed an improvement in progression-free survival. As a result, the trial was stopped by the Data Monitoring and Safety Committee but longer follow-up failed to show a survival advantage [9]. A similar trial by Pecorelli et al., assessing the addition of 6 cycles of paclitaxel after primary response to combination chemotherapy, failed to show benefit in PFS or OS [10]. In a novel approach, almost 20 years ago, maintenance subcutaneous interferon alpha or observation was explored in a randomised trial in women who had responded to chemotherapy and surgery. This trial also failed to show clinical benefit over standard of care [11].

It became clear that a maintenance strategy to sustain the benefit of primary treatment and prolong disease control and ultimately increase survival would depend on having a better understanding of the biology of ovarian cancer and developing approaches that would lead to a sustained process that targeted pathways involved in tumour growth and survival. In the last decade, a variety of strategies have emerged targeting tumour angiogenesis, DNA repair processes, and the host's immune system. Some of these have resulted in significant benefit and are re-shaping the way in which ovarian cancer is now being treated.

\section{Anti-Angiogenesis}

The role of angiogenesis is a well-known hallmark in cancer pathway [12]. In ovarian cancer, VEGF is known to play a role in peritoneal dissemination, tumour progression, and ascites formation [13, 14]. Two randomised trials, GOG 2018 and ICON7, explored the addition of bevacizumab, a monoclonal antibody that binds to VEGFA given with first-line chemotherapy and then as maintenance. The GOG 218 study was a three-arm placebo-controlled study in 1837 women with newly diagnosed, incompletely resected stage III-IV epithelial ovarian, tubal, or primary peritoneal cancer. Bevacizumab $(15 \mathrm{mg} / \mathrm{kg})$ was added to the two experimental arms - one receiving bevacizumab only concurrently with chemotherapy, and another arm continuing as maintenance therapy for total of 21 cycles [15]. In the ICON7 trial, 1528 patients with newly diagnosed stages I-IV epithelial ovarian, tubal, or primary peritoneal cancer were randomised to receive standard carboplatin and paclitaxel chemotherapy or the addition of bevacizumab $(7.5 \mathrm{mg} / \mathrm{kg})$, which was given concurrently with chemotherapy and continued every 3 weeks for total of 18 cycles [16]. The improvement in median PFS $[15,16]$ for both trials was about 2-4 months with the addition of bevacizumab. Additionally, a subgroup analysis in GOG 218 patients for whom increased CA125 result were censored, resulted in 6 months benefit compared to control group (12 vs 18 months, HR $0.645,95 \%$ CI, 0.551 to 0.756 ) [15] and as a result, bevacizumab of $15 \mathrm{mg} / \mathrm{kg}$ was approved by the EMA and many regulatory authorities around the world. However, there was no improvement in overall survival which was one reason for the delay in approval by the FDA. A retrospective subgroup analysis of ICON7 showed a survival benefit for bevacizumab in women with a higher risk of recurrence (Stage III with $\geq 2 \mathrm{~cm}$ residual disease/stage IV). The median OS was 39.7 versus 30.2 months (hazard ratio (HR) $0.78 ; 95 \%$ CI 0.63-0.97) [17]. In a similar analysis in stage IV patients treated in GOG 218, the median OS was 42.8 in the bevacizumab maintenance group compared to 32.6 months in the placebo-control arm ( HR 0.75 ; 95\% CI $0.59-0.95$ ) [18]. The treatment is generally well-tolerated with hypertension and proteinuria being the main side effects. Most patients were able to complete treatment, unless tumour progression occurred, and for many countries, bevacizumab, either at the full or half dose, was incorporated into treatment guidelines as a standard of care.

Three additional phase 3 trials have evaluated the efficacy of other anti-angiogenic agents. Two were with the oral broadspectrum tyrosine kinase inhibitors (TKIs) that both targeted the VEGF receptor. The design of these studies was broadly similar; the pazopanib study was a switch maintenance trial after chemotherapy and the nintedanib included patients treated during chemotherapy and as maintenance. Patients with stages II-IV EOC were included and both trials showed an improvement in median PFS; for pazopanib, there was a median PFS benefit of 5.6 months (HR 0.77 ; 95\% CI, 0.64-0.91; $p=.0021$ ) and for nintedanib it was 1.4 months (HR 0.84; $95 \%$ CI $0.72-0.98 ; p=0.024)$, respectively $[19,20]$. Final OS analysis of both trials did not show difference between treatment and placebo groups [21, 22]. While the HR for PFS in these studies was similar to bevacizumab, none of the oral tyrosine kinase inhibitors has been submitted for licensing for maintenance treatment in EOC.

The third trial, TRINOVA 3 , evaluated the addition of trebananib, a peptibody that interferes with the angiopoietin pathway neutralising the interaction between Ang1 and Ang2 and the Tie2 receptor in patients with advanced EOC. Treatment group received weekly intravenous trebananib concurrently with frontline chemotherapy and continued as maintenance for up to 18 months. Median PFS did not differ between the trebananib group (15.9 months) and the placebo group (15.0 months) (HR 0.93; 95\% CI 0.79-1.09; $p=0 \cdot 36$ ) [23].

Potential candidate predictors of response to VEGF inhibitors identified in the GOG 218, such as CD31 immunohistochemistry, failed to show a correlation with a response to treatment [18]. Translational studies from a cohort within the ICON7 trial proposed a discriminatory signature comprising mesothelin, fms-like tyrosine kinase-4 (FLT4), $\alpha-1$ acid 
glycoprotein (AGP), and cancer antigen 125 (CA-125) as potentially identifying those patients with EOC more likely to benefit from bevacizumab [24], as well as the potential role of Ang1 and Tie2 serum levels [25]. However, these markers need further validation in a broader group of patients from larger trials. The bevacizumab results met great enthusiasm which have been tempered by the results of the trials with oral anti-angiogenic agents, the lack of OS benefit from antiangiogenic therapy, and perhaps more importantly the absence of predictive markers of benefit.

\section{Poly-(ADP-Ribose) Polymerase Inhibitors}

The introduction of poly-(ADP-ribose) polymerase (PARP) inhibitors in the last decade has substantially changed the standard of care in the treatment of EOC. PARP enzymes are essential for the repair of single strand DNA breaks. Inhibition of PARP enzymes leads to an accumulation of double strand DNA breaks during replication and ultimately cell damage and death unless these DNA breaks can be repaired with high fidelity. Cancer cells with a BRCA mutation are deficient in the homologous recombination repair process (HRD), and are particularly sensitive to PARP inhibitors [26]. They are approved and widely used as maintenance therapy in platinum-responsive recurrent high-grade ovarian cancer following the publication of four trials with olaparib, niraparib, and rucaparib. HRD exists in a proportion of BRCA $^{\mathrm{wt}}$ tumours that respond to platinum-based therapy, and this has extended their use beyond tumours with a $\mathrm{BRCA}^{\mathrm{mut}}[27-31]$. As a consequence of these results, maintenance trials begun in the front-line setting, initially in patients with a BRCA ${ }^{\text {mut }}$. The first landmark in this area was the publication of the SOLO1 trial in which patients with stage III-IV high-grade serous or endometrioid ovarian, fallopian tube, or primary peritoneal cancer, with a germline or somatic BRCA1/2 mutation randomised to receive olaparib tablets or placebo for 24 months after completion of frontline platinumbased chemotherapy. The significant $70 \%$ reduction in the risk of disease progression or death in the olaparib arm (HR 0.30, 95\% CI 0.23-0.41) had never been seen before in this setting, making the results of this trial an important cornerstone in the current practice of treatment in ovarian cancer [32••]. Recently presented updated data have shown that at 5 years, $48 \%$ of patients treated with olaparib remain free of progression compared with $21 \%$ patients on placebo. The median PFS from the start of maintenance therapy is 56.0 months for olaparib versus 13.8 months in placebo (HR 0.33 ; 95\% CI $0.25-0.430$ ) [33••]. While OS data are not yet mature, these results underscore the value of using a PARP inhibitor as maintenance therapy in the first-line treatment of women with a BRCA mutation, and the importance of testing all patients for the presence of a germline or somatic BRCA mutation.
Recognising the value of PARP inhibitors in patients without BRCA mutations and with HRD in recurrent ovarian cancer, three further trials were conducted to explore the activity of PARP inhibitors in patients not selected for a BRCA mutation. Two of these trials had a switch maintenance design after first-line treatment with surgery and chemotherapy, adding niraparib or olaparib $[34 \bullet \bullet, 35 \bullet \cdot]$ and the third included the PARP inhibitor, veliparib with chemotherapy and then as maintenance [36••]. In the PRIMA trial, patients with FIGO stage III or IV high-grade serous or endometrioid randomised to receive oral niraparib or placebo after demonstrating a response to platinum-based chemotherapy. A planned hierarchical analysis first included patients with homologous recombination deficiency, defined as either having a deleterious BRCA $^{\text {mut }}$ or/a tumour HRD score, using the Myriad MyChoice test of at least 42, followed by the overall population. There followed an analysis in three subgroups: the

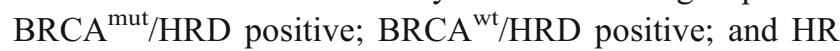
proficient groups. Significant prolongation of PFS seen with niraparib in all three groups, with diminishing benefit. The median PFS in each of the groups was, respectively, 22.1 months with niraparib versus 10.9 months with placebo (HR $0.43 ; 95 \% \mathrm{CI}, 0.31$ to $0.59 ; p<0.001), 19.6$ versus 8.2 months (HR $0.50(0.31-0.83)$ ), and 8.1 versus 5.4 months (HR0.68 $(0.49-0.94))[34 \cdot \bullet]$. As a result of the benefit in all three subgroups, niraparib maintenance is now widely licensed in all patients with stage III-IV high grade ovarian cancer.

A similar pattern of results was seen in the PAOLA-1 study in which patients received olaparib or placebo in addition to bevacizumab, given with chemotherapy and as maintenance. In addition to having two drugs during the maintenance phase, PAOLA-1 differed from PRIMA in that patients were not selected on the basis of a response to platinum-based therapy. Patients could enter if they were not progressing after primary treatment and included in this group were patients who had no evaluable disease after surgery (approximately $50 \%$ of the population). Similar benefits to PRIMA were seen among the HRD positive groups (using the Myriad assay), both with and without BRCA mutations but no benefit of adding olaparib to bevacizumab was seen in the HR proficient or unknown group. The median PFS in the three groups was 37.2 vs 17.7 months for patients with a tumour BRCA mutation (HR 0.33 ; $95 \%$ CI, 0.25 to 0.45 ); 28.1 vs 16.6 months in the HRD positive group without a BRCA mutation (HR 0.43; 95\% CI, 0.28 to 0.66 ); and 16.9 vs 16.0 months in the HRD proficient or unknown group (HR 0.92; 95\% CI, 0.72 to 1.17 ) $[35 \bullet \cdot]$.

Earlier studies using either an oral VEGF receptor tyrosine kinase inhibitor (cediranib) or bevacizumab in combination with a PARP inhibitor have shown an additive or synergistic effect compared with PARP inhibitor [37, 38]. However, as PAOLA-1 did not have an olaparib alone arm, it was not possible to examine if there was any beneficial interaction 
between bevacizumab and olaparib. Nevertheless, the combination of olaparib maintenance and bevacizumab is now widely licensed for patients who have a HRD-positive test, with or without the presence of a BRCA mutation [39].

In the VELIA trial, veliparib tablets were given concurrently with chemotherapy to patients with high grade serous EOC and continued as maintenance in one of the 3 trial arms. The median PFS for patients receiving veliparib maintenance was again longer in all patient populations, but most beneficial in the BRCA ${ }^{\text {mut }}$ and the HRD group of patients compared to the control group, 34.7 vs 22 months (HR 0.44 (95\% CI, 0.28 $0.68) ; p<0.001)$ and 31.9 vs 20.5 months (HR, $0.57 ; 95 \% \mathrm{CI}$, 0.43 to $0.76 ; p<0.001)$, respectively [36••]. Table 1 summarises frontline PARP inhibitor maintenance treatment trials at frontline with comparisons of their PFS.

Adverse events are not uncommon in patients treated with PARP inhibitors, especially in the initial months of treatment and often require careful counselling and dose modifications. The most common adverse effects include fatigue, anaemia, and nausea. However, more severe toxicity (grade 3 and above) is uncommon, and the majority of patients are able to continue treatment after treatment interruptions and dose reductions $[40,41]$.

There is little doubt about the benefit in patients with a BRCA mutation, and there are no clear differences between the activity of olaparib or niraparib in this subgroup. The situation for BRCA ${ }^{\mathrm{wt}}$ HRD-positive patients is a little more complicated. While the niraparib approval covers all patients in this group, the olaparib approval is with bevacizumab. Currently there is only one validated test for HRD, and more widely available tests are needed for simpler and cheaper access, and to clearly define this group. For patients with HR proficient tumours, there is greater uncertainty. While a benefit was apparent in the niraparib trial, no difference in outcome was seen when olaparib was added to bevacizumab. As pointed out, the entry criteria of patients in the PRIMA and PAOLA-1 trial are different, so that comparisons between the two trial outcomes should not be made. Clinicians, however, have the option of using niraparib in the HR proficient population. There is now widespread regulatory approval of PARP inhibitor maintenance therapy following first-line treatment. But it should be noted that longer-term outcome data for these patients is not yet available, and consideration needs to be given to whether all patients should receive maintenance with a PARP inhibitor at first-line or whether some women might derive greater benefit if these drugs are used in the setting of recurrent disease.

\section{Immunotherapy}

Abagovomab is a murine anti-idiotypic antibody whose variable epitope mimics the tumour antigen (CA-125). This mouse monoclonal antibody presents CA-125 to the immune system to enhance the immune response leading to recognition and killing of tumour cells expressing CA-125. The

Table 1 First line maintenance treatment trials with PARP inhibitor

\begin{tabular}{|c|c|c|c|c|}
\hline $\begin{array}{l}\text { Trial } \\
\text { name }\end{array}$ & Study group & Treatment arms & $\begin{array}{l}\text { Median PFS for control } \\
\text { group in months }\end{array}$ & $\begin{array}{l}\text { Median PFS for treatment } \\
\text { group in months (HR) }\end{array}$ \\
\hline SOLO1 & $\begin{array}{l}\text { Stage III-IV high grade EOC with } \\
\text { BRCA } 1 / 2 \text { mutation }\end{array}$ & $\begin{array}{l}\text { Arm 1: Olaparib 300mg BD } \\
\text { Arm 2: Placebo }\end{array}$ & 13.8 & $49.9(0.30)$ \\
\hline PRIMA & Stage III-IV high grade EOC & $\begin{array}{l}\text { Arm 1: Niraparib 300/200 mg OD } \\
\text { Arm 2: Placebo }\end{array}$ & $\begin{array}{l}\text { BRCA }^{\text {mut }}: 10.9 \\
\text { HRD: } 8.2 \\
\text { HRP: } 5.4\end{array}$ & $\begin{array}{l}\text { BRCA }^{\text {mut }}: 22.1(0.40) \\
\text { HRD: } 19.6(0.50) \\
\text { HRP: } 8.1(0.68)\end{array}$ \\
\hline VELIA & $\begin{array}{l}\text { Stage III-IV high grade } \\
\text { serous EOC }\end{array}$ & $\begin{array}{l}\text { Arm 1: Chemotherapy+ placebo followed } \\
\text { with placebo maintenance } \\
\text { Arm 2: Chemotherapy+ Veliparib } \\
\text { followed by placebo maintenance } \\
\text { Arm 3: Chemotherapy + Veliparib } 150 \mathrm{mg} \text {, } \\
\text { followed by Veliparib maintenance } \\
400 \mathrm{mg} \text { BD }\end{array}$ & $\begin{array}{l}\text { BRCA }^{\text {mut }}: 22.0 \\
\text { HRD: } 30.5 \\
\text { Intention to treat: } 7.3\end{array}$ & $\begin{array}{l}\text { BRCA }^{\text {mut: }}: 37.7(0.44) \\
\text { HRD: } 31.9(0.57) \\
\text { Intention to treat: } 23.5(0.68)\end{array}$ \\
\hline PAOLA1 & Stage III-IV high grade EOC & $\begin{array}{l}\text { Arm 1: Olaparib } 300 \mathrm{mg} \mathrm{BD} \\
\quad+\text { Bevacizumab } 15 \mathrm{mg} / \mathrm{kg} \mathrm{q} 3 \text { weeks } \\
\text { Arm 2: Placebo + Bevacizumab } 15 \mathrm{mg} / \mathrm{kg} \mathrm{q} \\
\quad 3 \text { weeks }\end{array}$ & $\begin{array}{l}\text { Tumour BRCA }{ }^{\text {mut }}: 21.7 \\
\text { Tumour BRCA -ve: } 16.0 \\
\text { HRD (+ BRCA } \\
\text { mut }): 17.7 \\
\text { HRD (without BRCA): } \\
\quad 16.6 \\
\text { HRP/unknown: } 16.0\end{array}$ & 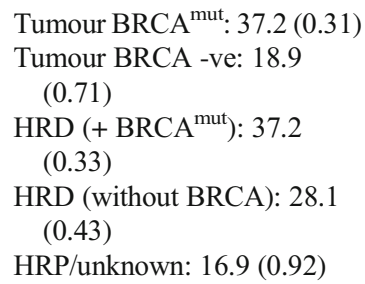 \\
\hline
\end{tabular}

$E O C$, epithelial ovarian cancer; $P F S$, progression-free survival; $H R$, hazard ratio; $H R D$, homologous recombination deficient; $H R P$, homologous recombination proficient 
MIMOSA study randomised in a 2:1 ratio nearly 900 patients with stage III to IV ovarian cancer in complete clinical remission after primary surgery and platinum- and taxane-based chemotherapy to abagovomab or placebo as maintenance therapy. However, maintenance abagovomab did not prolong recurrence free survival or OS [42].

It is now known that the immune system depends on various mechanisms, notably immune checkpoints, to maintain self-tolerance, prevent autoimmunity, and protect tissue from damage after activation of the immune response to pathogens. The immune system is heavily regulated through these checkpoint molecules, and this may explain why increased antigen presentation with abagovomab failed to generate a therapeutic immune response. Nevertheless, there are indicators to suggest that the tumour microenvironment in ovarian cancer is immunoreactive. Studies including a meta-analysis have shown that the presence of tumour-infiltrating lymphocytes (TILs) in ovarian cancer is associated with improved clinical outcome [43, 44]. Immunotherapy using checkpoint inhibitors (CPI), targeting CTLA-4, and/or PD-1/PD-L1 pathways has demonstrated a durable response in patients with certain solid tumours including melanoma, lung, bladder, and renal cancers. It is well established that CPI works by enhancing effector $\mathrm{T}$ cell responses, regardless of tumour type [45]. However, the results of studies with CPI in ovarian cancer have not thus far been encouraging. Early phase trials in advanced recurrent ovarian cancer have reported modest response rates of between 10 and $20 \%$, with up to $45 \%$ disease control rate [46-48], compared to other solid tumour types.

Notably, JAVELIN Ovarian 100 trial (NCT02718417), the first randomised first-line maintenance phase III trial was terminated prematurely due to lack of efficacy following a planned interim futility analysis after all patients had been accrued. The trial included 998 newly diagnosed untreated stage III-IV patients due to start platinum-based chemotherapy. Patients were randomised to receive 3-weekly avelumab (an anti-PD-L1 antibody) with chemotherapy, followed by maintenance or after chemotherapy as maintenance therapy or chemotherapy alone. Bevacizumab was not given [49]. Before the interim results of JAVELIN Ovarian 100 were available, another randomised phase III trial, JAVELIN Ovarian PARP 100 trial (NCT03642132) with avelumab, was started. This included the PARP inhibitor, talazoparib, and the standard of care control arm was chemotherapy with bevacizumab. The experimental arms were avelumab with chemotherapy and as maintenance with maintenance talazoparib, and talazoparib alone [50]. In view of the interim results of JAVELIN 100, the trial was terminated with only a few patients accrued. This was unfortunate, as the design allowed for comparisons with chemotherapy and bevacizumab and would have also given information on talazoparib alone and the combination with avelumab. These negative results have recently been followed by those of
IMagyn050/GOG 3015/ENGOT-OV39, a large phase III double-blind trial looking at a similar group of patients to JAVELIN Ovarian 100 trial. A total of 1301 women were randomised 1:1 to receive 3-weekly atezolizumab or placebo, with paclitaxel and carboplatin and then as maintenance for a total of 22 cycles. Bevacizumab was given to both arms for 22 cycles. After a median follow-up for 20 months, there was no statistically significant progression-free survival (PFS) improvement in either the intent-to-treat (ITT) population with a median of 18.4 months with placebo and 19.5 months with atezolizumab (HR 0.92; 95\% CI 0.79-1.07) or the PD-L1+ population with a median of 18.5 vs 20.8 months respectively (HR 0.80; 95\% CI 0.65-0.99). There was a trend towards a PFS benefit with atezolizumab in a subgroup with PD-L1 IC $\geq 5 \%$. The interim overall survival (OS) did not show a benefit for atezolizumab, although the data are immature [51]. Overall, these two trials have shown that immune checkpoint inhibitors alone do not improve the outcome of patients undergoing first-line therapy for ovarian cancer. Much of the investment now is in studies combining immune checkpoint inhibitors with PARP inhibitors with or without additional bevacizumab.

\section{Combining Targeted Therapies}

Understanding the factors responsible for generating tumour immunity and suppression is key to the success of immunotherapy in ovarian cancer, and it has been hypothesised that greater benefit can be achieved by combining different targeted therapies. Approximately 50\% of high-grade serous ovarian cancer have homologous recombination deficiency including BRCA1 and/or BRCA2 mutations, with over $90 \%$ have TP53 mutations [52], and these mutations may lead to increased genetic instability, potentially increasing tumour immunogenicity. Moreover, BRCA-mutated and TP53mutated ovarian cancer often contain increased number of tumour-infiltrating lymphocytes (TILs) and express PD-1/ PD-L1 [53, 54]. Coupled with the presence of TILs in these patients, this suggests that CPI should be effective in patients with ovarian cancer. However, we now understand that all steps in the cancer immunity cycle are important to harness an anti-tumour immune response [55]. The interaction between the immune system and tumour antigens is a cyclical process involving tumour antigen recognition by the immune system with antigen presentation first and foremost, before priming and activation of the immune system. It is now widely accepted that ovarian cancers not only have low tumour mutational burden [56], but also low T cell-gene expression profiles in about $70-75 \%$ of patients [57]. Moreover, ovarian cancer is strongly dominated by copy number alterations [58], and it has been shown that some of these alterations evade the immune system in other tumour types like lung 
Table 2 Phase III first-line trials with PARP inhibitors \pm VEGF inhibitors in combination with an immune checkpoint inhibitor (CPI)

\begin{tabular}{|c|c|c|c|c|c|}
\hline Trial name & $\begin{array}{l}\text { Trial details } \\
\text { (number, } \\
\text { completion date) }\end{array}$ & $\begin{array}{l}\text { PARP- } \\
\text { inhibitor }\end{array}$ & $\begin{array}{l}\text { Immune } \\
\text { checkpoint } \\
\text { inhibitor }\end{array}$ & Chemotherapy & Maintenance \\
\hline $\begin{array}{l}\text { ATHENA } \\
\text { (NCT03522246) }\end{array}$ & $\begin{array}{l}N=1000 \\
\text { December } 2024 \\
\text { Recruitment } \\
\quad \text { stopped }\end{array}$ & Rucaparib & Nivolumab & $\begin{array}{l}\text { Standard of care } \\
\quad \text { (not part of } \\
\text { trial) }\end{array}$ & $\begin{array}{l}\text { 1. Nivolumab + } \\
\text { Rucaparib } \\
\text { 2. Nivolumab } \\
\text { placebo + } \\
\text { Rucaparib } \\
\text { 3. Nivolumab + } \\
\text { Rucaparib } \\
\text { placebo } \\
\text { 4. Placebo + } \\
\text { Placebo }\end{array}$ \\
\hline $\begin{array}{l}\text { DUO-O } \\
\text { (NCT03737643) }\end{array}$ & $\begin{array}{l}N=1254 \\
\text { June } 2023 \\
\text { Still recruiting }\end{array}$ & Olaparib & Durvalumab & $\begin{array}{l}\text { Somatic BRCA } \\
\text { wildtype: } \\
\text { 1. CT + Bev + } \\
\text { placebo } \\
\text { 2. CT + Bev + } \\
\text { Durva } \\
\text { 3. CT + Bev + } \\
\text { Durva } \\
\text { Somatic BRCA } \\
\text { mutant: } \\
\text { 4. CT + Bev } \\
\text { (optional) + } \\
\text { Durva }\end{array}$ & $\begin{array}{l}\text { tBRCA wildtype: } \\
\text { 1. Bev + Durva } \\
\text { placebo + } \\
\text { Olaparib placebo } \\
\text { 2. Bev + Durva + } \\
\text { Olaparib placebo } \\
\text { 3. Bev + Durva + } \\
\text { Olaparib } \\
\text { tBRCA mutant: } \\
\text { 4. Bev (optional) + } \\
\text { Durva + Olaparib }\end{array}$ \\
\hline $\begin{array}{l}\text { MK-7339-001/KEYLYNK-001/ENGOT-ov43/GOG-3036 } \\
\text { (NCT03740165) }\end{array}$ & $\begin{array}{l}N=1086 \\
\text { August } 2025 \\
\text { Still recruiting }\end{array}$ & Olaparib & Pembrolizumab & $\begin{array}{l}\text { 1. } \mathrm{CT}+ \\
\text { pembrolizu- } \\
\text { mab } \\
\text { 2. } \mathrm{CT}+ \\
\text { pembrolizu- } \\
\text { mab } \\
\text { 3. } \mathrm{CT}+\text { placebo }\end{array}$ & $\begin{array}{l}\text { 1. Pembro + } \\
\text { Olaparib } \\
\text { 2. Pembro + placebo } \\
\text { 3. Placebo + } \\
\text { placebo }\end{array}$ \\
\hline $\begin{array}{l}\text { ENGOT-0V44 } \\
\text { FIRST trial } \\
\text { (NCT03602859) }\end{array}$ & $\begin{array}{l}N=1228 \\
\text { February } 2023 \\
\text { Still recruiting }\end{array}$ & Niraparib & $\begin{array}{l}\text { TSR-042 } \\
\text { (Dostarlima- } \\
\text { b) }\end{array}$ & $\begin{array}{l}\text { 1. CT }+ \\
\text { TSR- } 042 \\
\text { 2. CT } \\
\text { 3. CT }\end{array}$ & $\begin{array}{l}\text { 1. Niraparib + } \\
\text { TSR-042 } \\
\text { 2. Niraparib } \\
\text { 3. Placebo }\end{array}$ \\
\hline
\end{tabular}

Bev, bevacizumab; $C T$, chemotherapy; Durva, durvalumab; $N$, number

cancer [59, 60]. Moreover, tumour-associated macrophages (TAM), which have immunosuppressive effects, constitute a vital leucocyte population in ovarian cancer [61, 62]. Taken together, there are reasons why CPI, when used alone, has only yielded modest activity. It is crucial to re-examine the tumour microenvironment in ovarian cancer for changes preand post-treatment to help identify key changes to further increase efficacy of CPI [63-66]. In order to overcome these issues, several trials have been designed to enhance activation of the immune response by combining targeted therapies such as PARP and/or VEGF inhibitors. Many of these frontline maintenance trials are now underway and are summarised in Table 2. This has been a huge investment by the pharmaceutical industry, and a very large number of women have been enrolled in these trials. Also, these studies started before the results of the more recent PARP inhibitor studies which included $\mathrm{BRCA}^{\mathrm{wt}}$ patients became available. Whatever the outcome, it may be difficult to show that CPI combined with PARP inhibitors with or without bevacizumab augment the results we already have with PARP inhibitors alone or with bevacizumab.

\section{Hormonal Maintenance Therapy}

Immunohistochemistry demonstrates estrogen receptor (ER) in $43-81 \%$ of ovarian cancers [67]. Highest ER positivity has been reported in low-grade serous ovarian cancer (LGSOC), followed by high-grade endometrioid and serous EOC [68]. As LGSOC is known to have a more indolent course and a poorer response to standard chemotherapy, there has been much interest in exploring the possible clinical significance of the high percentage of ER and progesterone receptor (PR) positivity in these tumours. ER positivity in LGSOC has been 
found to be an independent prognostic variable for improved survival [67, 69] and treatment with tamoxifen, or aromatase inhibitors has shown clinical benefit in relapsed HGSOC. A study by Gershenson et al. demonstrated significantly longer PFS in a retrospective series of patients with LGSOC after primary surgery followed by platinum-based chemotherapy who received hormone maintenance treatment versus observation (64.9 vs 26.4 months, $p<.001$, respectively) [70]. Although randomised data are lacking in LGSOC, there is a generally held view that adjuvant chemotherapy has little benefit, so letrozole is being increasingly adopted as a standard after surgery. Formal testing is being undertaken in an NRG and National Cancer Institute (NCI) study in a phase III trial to assess non-inferiority of letrozole monotherapy versus platinum-based chemotherapy followed by maintenance letrozole for patients with newly diagnosed stage II-IV LGSOC after primary cytoreductive surgery. The results of this trial may shed more light on the treatment of LGSOC in the frontline setting (NCT04095364).

\section{Conclusion}

The paradigm of maintenance treatment in EOC has shifted largely during the last decade with the introduction of targeted treatments in the frontline maintenance setting. Despite variations in drug accessibility in different countries maintenance, therapy has become a standard of care for the treatment of advanced EOC. The use of bevacizumab has become widespread and the newer highly positive results of first-line PARP inhibitor trials underscore the importance for biomarkerdriven therapy. Testing for a BRCA mutation is now regarded as a standard investigation in patients with high grade EOC. The encouraging maturing results of PARP inhibitor maintenance in BRCA-mutated ovarian cancer provides optimism for a wider use of these drugs in HRD deficient tumours, particularly when testing for genomic instability becomes more readily available and widespread. Progress in bringing CPI into the treatment of ovarian cancer has been more challenging but the results of important trials combining CPI and PARP inhibitors will soon be available. It is becoming increasingly clear that the maintenance therapy is becoming the norm for first-line treatment, but this also opens up challenges for treating women who relapse after these treatments. More research is needed to see whether retreatment with PARP inhibitors or bevacizumab is possible, either alone, together, or in combination with other novel agents.

\section{Declarations}

Conflict of Interest Osnat Elyashiv and Yien Ning Sophia Wong declare no conflict of interest. Jonathan A. Ledermann is supported in part by institutional research grants from AstraZeneca and MSD/Merck; received compensation for participation on advisory boards from AstraZeneca, GlaxoSmithKline, MSD/Merck, Clovis Oncology, Eisai, Artios Pharma, and Pfizer; has received speaker's honoraria from AstraZeneca, GlaxoSmithKline, Clovis Oncology, and Eisai; and received compensation from Regeneron for participating on an independent data monitoring committee.

Human and Animal Rights and Informed Consent This article does not contain any studies with human or animal subjects performed by the authors.

Open Access This article is licensed under a Creative Commons Attribution 4.0 International License, which permits use, sharing, adaptation, distribution and reproduction in any medium or format, as long as you give appropriate credit to the original author(s) and the source, provide a link to the Creative Commons licence, and indicate if changes were made. The images or other third party material in this article are included in the article's Creative Commons licence, unless indicated otherwise in a credit line to the material. If material is not included in the article's Creative Commons licence and your intended use is not permitted by statutory regulation or exceeds the permitted use, you will need to obtain permission directly from the copyright holder. To view a copy of this licence, visit http://creativecommons.org/licenses/by/4.0/.

\section{References}

Papers of particular interest, published recently, have been highlighted as:

-• Of major importance

1. Bray F, Ferlay J, Soerjomataram I, Siegel RL, Torre LA, Jemal A. Global cancer statistics 2018: GLOBOCAN estimates of incidence and mortality worldwide for 36 cancers in 185 countries. CA Cancer J Clin. 2018;68(6):394-424. https://doi.org/10.3322/caac. 21492.

2. Kurman RJ. Origin and molecular pathogenesis of ovarian highgrade serous carcinoma. Ann Oncol. 2013;24 Suppl 10:x16-21. https://doi.org/10.1093/annonc/mdt463.

3. Hinchcliff EM, Bednar EM, Lu KH, Rauh-Hain JA. Disparities in gynecologic cancer genetics evaluation. Gynecol Oncol. 2019;153(1):184-91. https://doi.org/10.1016/j.ygyno.2019.01.024.

4. Kanchi KL, Johnson KJ, Lu C, McLellan MD, Leiserson MD, Wendl MC, et al. Integrated analysis of germline and somatic variants in ovarian cancer. Nat Commun. 2014;5:3156. https://doi.org/ $10.1038 /$ ncomms 4156 .

5. du Bois A, Reuss A, Pujade-Lauraine E, Harter P, Ray-Coquard I, Pfisterer J. Role of surgical outcome as prognostic factor in advanced epithelial ovarian cancer: a combined exploratory analysis of 3 prospectively randomized phase 3 multicenter trials: by the Arbeitsgemeinschaft Gynaekologische Onkologie Studiengruppe Ovarialkarzinom (AGO-OVAR) and the Groupe d'Investigateurs Nationaux Pour les Etudes des Cancers de l'Ovaire (GINECO). Cancer. 2009;115(6):1234 44. https://doi.org/10.1002/cncr.24149.

6. Jayson GC, Kohn EC, Kitchener HC, Ledermann JA. Ovarian cancer. Lancet. 2014;384(9951):1376-88. https://doi.org/10.1016/ s0140-6736(13)62146-7.

7. Rose PG, Java JJ, Salani R, Geller MA, Secord AA, Tewari KS, et al. Nomogram for predicting individual survival after recurrence of advanced-stage, high-grade ovarian carcinoma. Obstet Gynecol. 
2019;133(2):245-54. https://doi.org/10.1097/AOG. 0000000000003086 .

8. Markman M. Maintenance chemotherapy in the management of epithelial ovarian cancer. Cancer Metastasis Rev. 2015;34(1):117. https://doi.org/10.1007/s10555-014-9537-x.

9. Markman M, Liu PY, Wilczynski S, Monk B, Copeland LJ, Alvarez RD, Jiang C, et al. Phase III randomized trial of 12 versus 3 months of maintenance paclitaxel in patients with advanced ovarian cancer after complete response to platinum and paclitaxel-based chemotherapy: a Southwest Oncology Group and Gynecologic Oncology Group trial. 2003(0732-183X (Print)).

10. Pecorelli S, Favalli G, Gadducci A, Katsaros D, Panici PB, Carpi A, Scambia G, et al. Phase III trial of observation versus six courses of paclitaxel in patients with advanced epithelial ovarian cancer in complete response after six courses of paclitaxel/platinum-based chemotherapy: final results of the After-6 protocol 1. 2009(15277755 (Electronic)).

11. Hall GD, Brown JM, Coleman RE, Stead M, Metcalf KS, Peel KR, et al. Maintenance treatment with interferon for advanced ovarian cancer: results of the Northern and Yorkshire gynaecology group randomised phase III study. Br J Cancer. 2004;91(4):621-6. https:// doi.org/10.1038/sj.bjc.6602037.

12. Hanahan D, Weinberg RA. Hallmarks of cancer: the next generation. Cell. 2011;144(5):646-74. https://doi.org/10.1016/j.cell.2011. 02.013 .

13. Duncan TJ, Al-Attar A, Rolland P, Scott IV, Deen S, Liu DT, et al. Vascular endothelial growth factor expression in ovarian cancer: a model for targeted use of novel therapies? Clin Cancer Res. 2008;14(10):3030-5. https://doi.org/10.1158/1078-0432.CCR-071888.

14. Yamamoto S, Konishi I, Mandai M, Kuroda H, Komatsu T, Nanbu $\mathrm{K}$, et al. Expression of vascular endothelial growth factor (VEGF) in epithelial ovarian neoplasms: correlation with clinicopathology and patient survival, and analysis of serum VEGF levels. Br J Cancer. 1997;76(9):1221-7. https://doi.org/10.1038/bjc.1997.537.

15. Burger RA, Brady MF, Bookman MA, Fleming GF, Monk BJ, Huang $\mathrm{H}$, et al. Incorporation of bevacizumab in the primary treatment of ovarian cancer. N Engl J Med. 2011;365(26):2473-83. https://doi.org/10.1056/NEJMoa1104390.

16. Perren TJ, Swart AM, Pfisterer J, Ledermann JA, Pujade-Lauraine E, Kristensen G, et al. A phase 3 trial of bevacizumab in ovarian cancer. N Engl J Med. 2011;365(26):2484-96. https://doi.org/10. 1056/NEJMoa1 103799

17. Oza AM, Cook AD, Pfisterer J, Embleton A, Ledermann JA, Pujade-Lauraine E, et al. Standard chemotherapy with or without bevacizumab for women with newly diagnosed ovarian cancer (ICON7): overall survival results of a phase 3 randomised trial. Lancet Oncol. 2015;16(8):928-36. https://doi.org/10.1016/s14702045(15)00086-8

18. Tewari KS, Burger RA, Enserro D, Norquist BM, Swisher EM, Brady MF, et al. Final overall survival of a randomized trial of bevacizumab for primary treatment of ovarian cancer. J Clin Oncol. 2019;37(26):2317-28. https://doi.org/10.1200/jco.19. 01009.

19. du Bois A, Floquet A, Kim JW, Rau J, del Campo JM, Friedlander $\mathrm{M}$, et al. Incorporation of pazopanib in maintenance therapy of ovarian cancer. J Clin Oncol. 2014;32(30):3374-82. https://doi. org/10.1200/jco.2014.55.7348.

20. du Bois A, Kristensen G, Ray-Coquard I, Reuss A, Pignata S, Colombo N, et al. Standard first-line chemotherapy with or without nintedanib for advanced ovarian cancer (AGO-OVAR 12): a randomised, double-blind, placebo-controlled phase 3 trial. Lancet Oncol. 2016;17(1):78-89. https://doi.org/10.1016/s1470-2045(15) 00366-6.

21. Vergote I, du Bois A, Floquet A, Rau J, Kim JW, Del Campo JM, et al. Overall survival results of AGO-OVAR16: a phase 3 study of maintenance pazopanib versus placebo in women who have not progressed after first-line chemotherapy for advanced ovarian cancer. Gynecol Oncol. 2019;155(2):186-91. https://doi.org/10.1016/ j.ygyno.2019.08.024.

22. Ray-Coquard I, Cibula D, Mirza MR, Reuss A, Ricci C, Colombo $\mathrm{N}$, et al. Final results from GCIG/ENGOT/AGO-OVAR 12, a randomised placebo-controlled phase III trial of nintedanib combined with chemotherapy for newly diagnosed advanced ovarian cancer. Int J Cancer. 2020;146(2):439-48. https://doi.org/10.1002/ ijc.32606.

23. Vergote I, Scambia G, O'Malley DM, Van Calster B, Park S-Y, del Campo JM, et al. Trebananib or placebo plus carboplatin and paclitaxel as first-line treatment for advanced ovarian cancer (TRINOVA-3/ENGOT-ov2/GOG-3001): a randomised, doubleblind, phase 3 trial. Lancet Oncol. 2019;20(6):862-76. https://doi. org/10.1016/s1470-2045(19)30178-0.

24. Collinson F, Hutchinson M, Craven RA, Cairns DA, Zougman A, Wind TC, et al. Predicting response to bevacizumab in ovarian cancer: a panel of potential biomarkers informing treatment selection. Clin Cancer Res. 2013;19(18):5227-39. https://doi.org/10. 1158/1078-0432.CCR-13-0489.

25. Backen A, Renehan AG, Clamp AR, Berzuini C, Zhou C, Oza A, et al. The combination of circulating Ang1 and Tie2 levels predicts progression-free survival advantage in bevacizumab-treated patients with ovarian cancer. Clin Cancer Res. 2014;20(17):454958. https://doi.org/10.1158/1078-0432.CCR-13-3248.

26. Farmer H, McCabe N, Lord CJ, Tutt AN, Johnson DA, Richardson TB, et al. Targeting the DNA repair defect in BRCA mutant cells as a therapeutic strategy. Nature. 2005;434(7035):917-21. https://doi. org/10.1038/nature03445.

27. Ledermann J, Harter P, Gourley C, Friedlander M, Vergote I, Rustin $\mathrm{G}$, et al. Olaparib maintenance therapy in platinumsensitive relapsed ovarian cancer. N Engl J Med. 2012;366(15): 1382-92. https://doi.org/10.1056/NEJMoa1105535.

28. Ledermann J, Harter P, Gourley C, Friedlander M, Vergote I, Rustin G, et al. Olaparib maintenance therapy in patients with platinum-sensitive relapsed serous ovarian cancer: a preplanned retrospective analysis of outcomes by BRCA status in a randomised phase 2 trial. Lancet Oncol. 2014;15(8):852-61. https://doi.org/10. 1016/S1470-2045(14)70228-1.

29. Pujade-Lauraine E, Ledermann JA, Selle F, Gebski V, Penson RT, Oza AM, et al. Olaparib tablets as maintenance therapy in patients with platinum-sensitive, relapsed ovarian cancer and a BRCA1/2 mutation (SOLO2/ENGOT-Ov21): a double-blind, randomised, placebo-controlled, phase 3 trial. Lancet Oncol. 2017;18(9):1274 84. https://doi.org/10.1016/s1470-2045(17)30469-2.

30. Mirza MR, Monk BJ, Herrstedt J, Oza AM, Mahner S, Redondo A, et al. Niraparib maintenance therapy in platinum-sensitive, recurrent ovarian cancer. N Engl J Med. 2016;375(22):2154-64. https:// doi.org/10.1056/NEJMoa1611310.

31. Coleman RL, Oza AM, Lorusso D, Aghajanian C, Oaknin A, Dean A, et al. Rucaparib maintenance treatment for recurrent ovarian carcinoma after response to platinum therapy (ARIEL3): a randomised, double-blind, placebo-controlled, phase 3 trial. Lancet. 2017;390(10106):1949-61. https://doi.org/10.1016/s01406736(17)32440-6.

32.• Moore K, Colombo N, Scambia G, Kim BG, Oaknin A, Friedlander $\mathrm{M}$, et al. Maintenance olaparib in patients with newly diagnosed advanced ovarian cancer. N Engl J Med. 2018;379(26):2495-505. https://doi.org/10.1056/NEJMoa1810858 A radomised phase III trial of patients with stage III/IV high grade serous or endometrioid ovarian, fallopian or primary peritoneal cancer, with BRCA1 or BRCA2 mutation, who responded to frontline platinum based chemotherapy to receive olaparib or placebo maitenance. The trial showed a substantial PFS benefit for patients who received olaparib. 
33.• Banerjee S, Moore KN, Colombo N, Scambia G, Kim BG, Oaknin A, et al. 811MO Maintenance olaparib for patients (pts) with newly diagnosed, advanced ovarian cancer (OC) and a BRCA mutation (BRCAm): 5-year (y) follow-up (f/u) from SOLO1. Ann Oncol. 2020;31:S613. https://doi.org/10.1016/j.annonc.2020.08.950 Published OS data from SOLO1, a phase III radndomised controlled trial of patients with newly diagnosed advanced ovarian cancer with BRCA mutation receiving olaparib or placebo after completion of frontline platinum based chemotherapy. This shows significan OS benefit for patients receiving olaparib.

34.• Gonzalez-Martin A, Pothuri B, Vergote I, DePont Christensen R, Graybill W, Mirza MR, et al. Niraparib in patients with newly diagnosed advanced ovarian cancer. N Engl J Med. 2019;381(25):2391-402. https://doi.org/10.1056/ NEJMoa1910962 A randomised phase III trial for patients with newly diagnosed advanced high-grade ovarian cancer who responded to platinum-based chemotherapy to receive niraparib or placebo for up to 3 years regardless of a BRCA mutation status. A significant PFS prolongation was seen in all patients, with greatest benefit seen in patients harbouring a BRCA mutation or homologous recombination deficient (HRD) tumours.

35.• Ray-Coquard I, Pautier P, Pignata S, Perol D, Gonzalez-Martin A, Berger R, et al. Olaparib plus bevacizumab as first-line maintenance in ovarian cancer. N Engl J Med. 2019;381(25):2416-28. https:// doi.org/10.1056/NEJMoa1911361 Randomised phase III trial for patients with newly diagnosed advanced high grade ovarian cancer responding to fron line platinum-taxane chemotherapy plus bevacisumab to receive oplaparib or placebo. A significant PFS prolongation was seen in the olaparib group for patients with homologous recombination deficiency (HRD).

36.• Coleman RL, Fleming GF, Brady MF, Swisher EM, Steffensen $\mathrm{KD}$, Friedlander M, et al. Veliparib with first-line chemotherapy and as maintenance therapy in ovarian cancer. N Engl J Med. 2019;381(25):2403-15. https://doi.org/10.1056/NEJMoa1909707 A randomised phase III trial for patients with newly diagnosed stage III/IV high-grade serous ovarian cancer who responded to carboplatin and paclutaxel, regardless of BRCA mutation status. Patients radomised to receive chemotherapy plus placebo followed by placebo maintenance (control), chemotherapy plus veliparib followed by placebo (veliparib combination) or chemotherapy plus veliparib followed by veliparib maintenance (veliparib troughout). significant PFS prolongation was seen across all patients who received veliparib troughout, with the greates benefit seen in patients with BRCA mutation and homologous recombination deficient (HRD) tumours.

37. Liu JF, Barry WT, Birrer M, Lee JM, Buckanovich RJ, Fleming $\mathrm{GF}$, et al. Combination cediranib and olaparib versus olaparib alone for women with recurrent platinum-sensitive ovarian cancer: a randomised phase 2 study. Lancet Oncol. 2014;15(11):1207-14. https://doi.org/10.1016/S1470-2045(14)70391-2.

38. Mirza MR, Mortensen CE, Avall-Lundqvist E, Bjorge L, Berek JS, Herrstedt J, et al. ENGOT-OV24-NSGO/AVANOVA: niraparib versus bevacizumab-niraparib combination versus bevacizumab and niraparib as sequential therapy in women with platinumsensitive epithelial ovarian, fallopian tube, or peritoneal cancer. J Clin Oncol. 2015;33(15_suppl):TPS5607-TPS. https://doi.org/10. 1200/jco.2015.33.15_suppl.tps5607.

39. Arora S, Balasubramaniam S, Zhang H, Berman T, Narayan P, Suzman D, et al. FDA Approval Summary: Olaparib Monotherapy or in Combination with Bevacizumab for the Maintenance Treatment of Patients with Advanced Ovarian Cancer. Oncologist. 2020;26:e164-72. https://doi.org/10.1002/ onco.13551.
40. Madariaga A, Bowering V, Ahrari S, Oza AM, Lheureux S. Manage wisely: poly (ADP-ribose) polymerase inhibitor (PARPi) treatment and adverse events. Int J Gynecol Cancer. 2020;30(7): 903-15. https://doi.org/10.1136/ijgc-2020-001288.

41. LaFargue CJ, Dal Molin GZ, Sood AK, Coleman RL. Exploring and comparing adverse events between PARP inhibitors. Lancet Oncol. 2019;20(1):e15-28. https://doi.org/10.1016/S14702045(18)30786-1.

42. Sabbatini P, Harter P, Scambia G, Sehouli J, Meier W, Wimberger $\mathrm{P}$, et al. Abagovomab as maintenance therapy in patients with epithelial ovarian cancer: a phase III trial of the AGO OVAR, COGI, GINECO, and GEICO-the MIMOSA study. J Clin Oncol. 2013;31(12):1554-61. https://doi.org/10.1200/jco.2012.46.4057.

43. Zhang L, Conejo-Garcia JR, Katsaros D, Gimotty PA, Massobrio $\mathrm{M}$, Regnani $\mathrm{G}$, et al. Intratumoral $\mathrm{T}$ cells, recurrence, and survival in epithelial ovarian cancer. N Engl J Med. 2003;348(3):203-13. https://doi.org/10.1056/NEJMoa020177.

44. Hwang WT, Adams SF, Tahirovic E, Hagemann IS, Coukos G. Prognostic significance of tumor-infiltrating T cells in ovarian cancer: a meta-analysis. Gynecol Oncol. 2012;124(2):192-8. https:// doi.org/10.1016/j.ygyno.2011.09.039.

45. Sharma P, Allison JP. The future of immune checkpoint therapy Science. 2015;348(6230):56-61. https://doi.org/10.1126/science. aaa8172.

46. Matulonis UA, Shapira-Frommer R, Santin AD, Lisyanskaya AS, Pignata S, Vergote I, et al. Antitumor activity and safety of pembrolizumab in patients with advanced recurrent ovarian cancer: results from the phase II KEYNOTE-100 study. Ann Oncol. 2019;30(7):1080-7. https://doi.org/10.1093/annonc/mdz135.

47. Hamanishi J, Mandai M, Ikeda T, Minami M, Kawaguchi A, Murayama T, et al. Safety and antitumor activity of anti-pd-1 antibody, nivolumab, in patients with platinum-resistant ovarian cancer. J Clin Oncol. 2015;33(34):4015-22. https://doi.org/10.1200/ JCO.2015.62.3397.

48. Liu JF, Gordon M, Veneris J, Braiteh F, Balmanoukian A, Eder JP, et al. Safety, clinical activity and biomarker assessments of atezolizumab from a Phase I study in advanced/recurrent ovarian and uterine cancers. Gynecol Oncol. 2019;154(2):314-22. https:// doi.org/10.1016/j.ygyno.2019.05.021.

49. Ledermann JA, Colombo N, Oza AM, Fujiwara K, Birrer MJ, Randall LM, et al. Avelumab in combination with and/or following chemotherapy vs chemotherapy alone in patients with previously untreated epithelial ovarian cancer: results from the phase 3 javelin ovarian 100 trial. Gynecol Oncol. 2020;159:13-4. https://doi.org/ 10.1016/j.ygyno.2020.06.025.

50. Eskander RN, Ledermann JA, Birrer MJ, Fujiwara K, Gaillard S, Richardson GE, et al. JAVELIN ovarian PARP 100 study design: phase III trial of avelumab + chemotherapy followed by avelumab + talazoparib maintenance in previously untreated epithelial ovarian cancer. J Clin Oncol. 2019;37(8 suppl):TPS9-TPS. https://doi.org/ 10.1200/JCO.2019.37.8_suppl.TPS9.

51. Moore KN, Bookman M, Sehouli J, Miller A, Anderson C, Scambia G, et al. LBA31 Primary results from IMagyn050/GOG 3015/ENGOT-OV39, a double-blind placebo (pbo)-controlled randomised phase III trial of bevacizumab (bev)-containing therapy +/- atezolizumab (atezo) for newly diagnosed stage III/IV ovarian cancer (OC). Ann Oncol. 2020;31:S1161-S2. https://doi.org/10. 1016/j.annonc.2020.08.2261.

52. Cancer Genome Atlas Research N. Integrated genomic analyses of ovarian carcinoma. Nature. 2011;474(7353):609-15. https://doi. org/10.1038/nature10166.

53. Strickland KC, Howitt BE, Shukla SA, Rodig S, Ritterhouse LL, Liu JF, et al. Association and prognostic significance of BRCA1/2mutation status with neoantigen load, number of tumor-infiltrating lymphocytes and expression of PD-1/PD-L1 in high grade serous 
ovarian cancer. Oncotarget. 2016;7(12):13587-98. https://doi.org/ 10.18632/oncotarget.7277.

54. Wieser V, Gaugg I, Fleischer M, Shivalingaiah G, Wenzel S, Sprung S, et al. BRCA1/2 and TP53 mutation status associates with PD-1 and PD-L1 expression in ovarian cancer. Oncotarget. 2018;9(25):17501-11. https://doi.org/10.18632/oncotarget.24770.

55. Chen DS, Mellman I. Oncology meets immunology: the cancerimmunity cycle. Immunity. 2013;39(1):1-10. https://doi.org/10. 1016/j.immuni.2013.07.012.

56. Alexandrov LB, Nik-Zainal S, Wedge DC, Aparicio SA, Behjati S, Biankin AV, et al. Signatures of mutational processes in human cancer. Nature. 2013;500(7463):415-21. https://doi.org/10.1038/ nature 12477

57. Cristescu R, Mogg R, Ayers M, Albright A, Murphy E, Yearley J, et al. Pan-tumor genomic biomarkers for PD-1 checkpoint blockade-based immunotherapy. Science. 2018;362(6411). https:// doi.org/10.1126/science.aar3593.

58. Ciriello G, Miller ML, Aksoy BA, Senbabaoglu Y, Schultz N, Sander C. Emerging landscape of oncogenic signatures across human cancers. Nat Genet. 2013;45(10):1127-33. https://doi.org/10. 1038/ng.2762.

59. McGranahan N, Rosenthal R, Hiley CT, Rowan AJ, Watkins TBK, Wilson GA, et al. Allele-specific HLA loss and immune escape in lung cancer evolution. Cell. 2017;171(6):1259-71 e11. https://doi. org/10.1016/j.cell.2017.10.001.

60. Rosenthal R, Cadieux EL, Salgado R, Bakir MA, Moore DA, Hiley $\mathrm{CT}$, et al. Neoantigen-directed immune escape in lung cancer evolution. Nature. 2019;567(7749):479-85. https://doi.org/10.1038/ s41586-019-1032-7.

61. Yuan X, Zhang J, Li D, Mao Y, Mo F, Du W, et al. Prognostic significance of tumor-associated macrophages in ovarian cancer: A meta-analysis. Gynecol Oncol. 2017;147(1):181-7. https://doi.org/ 10.1016/j.ygyno.2017.07.007.

62. Ruffell B, Coussens LM. Macrophages and therapeutic resistance in cancer. Cancer Cell. 2015;27(4):462-72. https://doi.org/10.1016/ j.ccell.2015.02.015.

63. Chen PL, Roh W, Reuben A, Cooper ZA, Spencer CN, Prieto PA, et al. Analysis of immune signatures in longitudinal tumor samples yields insight into biomarkers of response and mechanisms of resistance to immune checkpoint blockade. Cancer Discov. 2016;6(8):827-37. https://doi.org/10.1158/2159-8290.Cd-151545.

64. Wong YNS, Joshi K, Khetrapal P, Ismail M, Reading JL, Sunderland MW, et al. Urine-derived lymphocytes as a noninvasive measure of the bladder tumor immune microenvironment. J Exp Med. 2018;215(11):2748-59. https://doi.org/10.1084/jem. 20181003.

65. Tumeh PC, Harview CL, Yearley JH, Shintaku IP, Taylor EJ, Robert L, et al. PD-1 blockade induces responses by inhibiting adaptive immune resistance. Nature. 2014;515(7528):568-71. https://doi.org/10.1038/nature13954.

66. Herbst RS, Soria JC, Kowanetz M, Fine GD, Hamid O, Gordon MS, et al. Predictive correlates of response to the anti-PD-L1 antibody MPDL3280A in cancer patients. Nature. 2014;515(7528): 563-7. https://doi.org/10.1038/nature14011.

67. Shen Z, Luo H, Li S, Sheng B, Zhao M, Zhu H, et al. Correlation between estrogen receptor expression and prognosis in epithelial ovarian cancer: a meta-analysis. Oncotarget. 2017;8(37):62400 13. https://doi.org/10.18632/oncotarget.18253.

68. Sieh W, Köbel M, Longacre TA, Bowtell DD. deFazio A, Goodman MT, et al. Hormone-receptor expression and ovarian cancer survival: an Ovarian Tumor Tissue Analysis consortium study. Lancet Oncol. 2013;14(9):853-62. https://doi.org/10.1016/ s1470-2045(13)70253-5.

69. Llaurado Fernandez M, Dawson A, Kim H, Lam N, Russell H, Bruce $\mathrm{M}$, et al. Hormone receptor expression and outcomes in low-grade serous ovarian carcinoma. Gynecol Oncol. 2020;157(1):12-20. https://doi.org/10.1016/j.ygyno.2019.11.029.

70. Gershenson DM, Bodurka DC, Coleman RL, Lu KH, Malpica A, Sun CC. Hormonal Maintenance Therapy for Women With LowGrade Serous Cancer of the Ovary or Peritoneum. J Clin Oncol. 2017;35(10):1103-11. https://doi.org/10.1200/JCO.2016.71.0632.

Publisher's Note Springer Nature remains neutral with regard to jurisdictional claims in published maps and institutional affiliations. 